\title{
VARIABILIDAD EN LA RESISTENCIA A MANCHA AMARILLA EN GENOTIPOS DE TRIGOS PRIMAVERALES DE DIVERSOS ORÍGENES
}

\author{
Uranga, J.P. ${ }^{1,2} ;$ Schierenbeck, M. ${ }^{1,2} ;$ Perelló, A.e. ${ }^{2,3} ;$ \\ BORNER, A. ${ }^{4}$ \& SIMÓN, M.R. ${ }^{1}$
}

\begin{abstract}
RESUMEN
La mancha amarilla producida por Pyrenophora tritici-repentis (Died.) Drechs. (anamorph Drechslera tritici-repentis (Died.) Shoem.) es una de las enfermedades más importantes que afectan al trigo. El objetivo de este trabajo fue generar información acerca de la variabilidad en la resistencia a mancha amarilla en una población de genotipos de trigos primaverales previamente mapeada. El experimento fue realizado a campo en la Estación Experimental Julio Hirschhorn (EEJH) de la Universidad Nacional de La Plata (UNLP). El diseño experimental fue de parcela dividida con dos repeticiones. La parcela principal fueron dos aislados de P. tritici-repentis y la subparcela fueron 110 genotipos. Se evaluó la severidad en plántula como porcentaje de área afectada por clorosis y necrosis. Los genotipos y aislados presentaron diferencias significativas. El aislado Los Hornos se mostró más agresivo que el aislado Gualeguaychú. La severidad varió entre 18,4 y 78,7\%, con algunos genotipos que mostraron comportamientos diferenciales entre aislados. La alta variabilidad en la resistencia frente a mancha amarilla encontrada puede ser de utilidad en mejoramiento genético. Palabras clave: Pyrenophora tritici-repentis; Mancha amarilla; Resistencia; Variabilidad; Trigo.
\end{abstract}

\section{ABSTRACT}

\section{Variability on tan spot resistance of spring wheat genotypes from diverse} origins.

Tan spot caused by Pyrenophora tritici-repentis (Died.) Drechs. (anamorph Drechslera tritici-repentis (Died.) Shoem.) is one of the most important wheat diseases. The aim of this work was to generate information about variability of the resistance to tan spot in a population of spring wheat genotypes. Field experiments were carried out in 2014 at the Experimental Station Julio Hirs

1.- Cerealicultura, Facultad de Ciencias Agrarias y Forestales, Universidad Nacional de La Plata, La Plata, Argentina. Email: mrsimon@agro.unlp.edu.ar

2.- CONICET, La Plata, Argentina.

3.- Centro de Investigaciones de Fitopatología (CIDEFI), Facultad de Ciencias Agrarias y Forestales, Universidad Nacional de La Plata, La Plata, Argentina.

4.- Leibniz-Institute for Plant Genetics and Plant Crop Research (IPK), Gatersleben, Germany.

Manuscrito recibido el 28 de julio de 2015 y aceptado para su publicación el 11 de diciembre de 2015. 
chhorn, National University of La Plata. The experimental design was a split-plot with two replications. The main plots were two isolates of P. tritici-repentis. Subplots were 110 spring wheat genotypes. Severity evaluation was performed in seedlings as the area affected with necrosis and chlorosis. Genotypes and isolates significanlty influenced the disease severity. Los Hornos isolate was more aggressive than Gualeguaychú isolate. Severity ranged between $18,4 \%$ to $78,7 \%$. Some genotypes showed better performance against one of the isolates. The high variability in resistance to tan spot found could be used in breeding to improve the resistance to the disease. Key words: Pyrenophora tritici-repentis; Tan spot; Resistance; Variability; Wheat.

\section{INTRODUCCIÓN}

Una de las principales limitantes biológicas que reducen la expresión de la potencialidad de los rendimientos del cultivo de trigo en la Argentina son las enfermedades (4). Los agentes causales de estas enfermedades, principalmente de origen micótico, parasitan los tejidos de la raíz, tallos, hojas, espigas y granos. Las enfermedades foliares del trigo se han incrementado en los últimos años en Argentina, debido a factores culturales, tales como el incremento de la siembra directa, como así también la susceptibilidad de los cultivares y la alta variabilidad genética de los patógenos causales (1). La mancha amarilla producida por Pyrenophora tritici-repentis (Died.) Drechs. (anamorph Drechslera tritici-repentis (Died.) Shoem.) es una de las enfermedades más importantes que afectan al trigo.

El hongo $P$. tritici-repentis se encuentra distribuido en las principales zonas de cultivo del trigo. Este patógeno induce la formación de manchas necróticas en las hojas, que se rodean de un halo clorótico y produce exotoxinas involucradas en el desarrollo de síntomas de la enfermedad. El hongo produce básicamente tres toxinas denominadas ToxA, ToxB y Toxb con receptores específicos en el hospedante (16). El área foliar enferma resta a la hoja capacidad fotosintética pudiéndose ver afectado de manera importante el rendimiento en grano cuando existe alta susceptibilidad del cultivar a la enfermedad.

El ciclo de vida del patógeno se encuentra altamente relacionado con los sistemas conservacionistas (rastrojos en superficie). La cantidad de rastrojo infectado está correlacionado con la severidad de la enfermedad y las pérdidas en producción (8). En particular, la enfermedad se incrementa en siembra directa de trigo en monocultivo $(10,15)$. La presencia de otros hospedantes es una fuente de inóculo primario y reservorio de una población del patógeno genéticamente diferente de la que prevalece en trigo (9) y de amplia diversidad genética y patogénica en Argentina (13).

El control de esta enfermedad en el contexto del manejo integrado implica la combinación de resistencia genética, prácticas culturales (rotaciones, densidad, fecha de siembra, fertilización) control biológico y químico (2, 5, 6, 12,15).

La resistencia genética es la base del manejo integrado, ya que tiene una baja relación costo/beneficio y preserva el medio ambiente. La resistencia es una reacción de defensa del hospedante, resultante de una suma de factores que tienden a disminuir la agresividad y / o la virulencia del patógeno, una vez establecido el contacto con el hospedante (7). La resistencia disponible frente a mancha amarilla es de tipo parcial o in- 